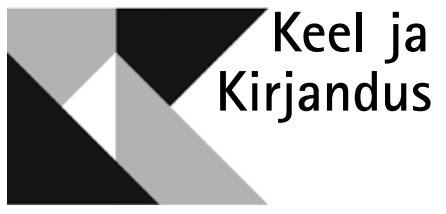

\title{
JAN KAUSI LINN
}

\author{
ELLE-MARI TALIVEE
}

$\mathrm{J}$ an Kaus on kirjutanud Tallinnast ja Tallinnale. Küllap on ta seejuures lähtunud ka iseenda väitest, et Tallinn - ja nii iga linn - ei saa olla üks raamat, vaid terve riiulitäis raamatuid (Kaus 2004: 68). Romaan „Hetk” (2009) on autori määratluses armastus- ja vihakiri kodulinnale (vt Sibrits 2010), eraldi peatükiga „Tallinn, mu Tallinn”. Linnakujutuse ehedust on toonitatud 2012. aastal ilmunud romaanis „Koju” (Helme 2013). Miniatuuridekogu „Tallinna kaart” (Kaus 2014b) kandis esialgu pealkirja „Armastuslaulud” $\left(\right.$ Kaus 2015) ${ }^{1}$ - needki siis nimetatud linnale. Ka Kausi viimases, hoopis salapärasest Tarurootsist kõnelevas romaanis „Ma olen elus” (2014a) visandatakse Tallinna mõne üksiku mõjusa tõmbega. Lisaks on kirjanikule korda läinud mitmesugune Tallinna-teemaline kriitika ja esseistika (heaks näiteks on tema artikkel „Jalutades Vana-Kalamaja tänaval”, vt Kaus 2002). Seejuures on teda ajendanud katse „leida oma linnast üles see „miski”, mis paneb linna ikka ja jälle mõtetesse, kirjandusse, unedesse tagasi tulema, mis teeb linnast kummitava ja katuseta labürindi, mis on tulvil õhulisi ning hämmastavaid paiku" (Kaus 2005). Tallinna-kujutus on autori sõnul olnud kantud laiemast lähedustundest, mis „kuulub pigem mälule ja kujutlusvõimele kui kehadele” (Kaus 2015).

${ }^{1}$ Kultuurkapitali kirjanduse sihtkapitali aastaauhinna kõnes tänas Jan Kaus Kai Aareleidi kui „Tallinna kaardi” ristiema. Küsisin käesolevat artiklit kirjutama hakates temalt e-kirjas, milline oli algne pealkiri ja kas võin seda mainida. Viidatud on Jan Kausi vastusele, kus ta avas ka pealkirja tagamaid. 
Mõned linnaga tihedalt seotud motiivid, omamoodi koelõngad, jooksevad ühest Kausi raamatust teise: linn tekib ikka kas jalutajate või autosõitjate (näiteks taksojuhi) rännakuist ja seda ilmestab intensiivselt kohanimede nimetamine - tänavanimed funktsioneerivad „kui „anumad”, lähte- ja tõukekohad" (Kaus 2015). Kahtlemata on Kausi kirjanduslik Tallinn erinevate mälestuste reservuaar, olgu need siis fragmentaarsed, nagu üks linn isegi on (võib oletada, et mitugi unustatud asja linna lähiminevikust ärkavad just tekstides, olgu näiteks kaheksakümnendate aastate talvede pime Tallinn). Rohkem tundub vihjeid olevat varasemale kui tänapäeva linnale, teisalt on kujutatu üsna lähiajalooline - praeguse linna taustal ikka veel aimatav paik, kui hoolega vaadata.

\section{Tees: „miski” kui linnalabürindi läbikirjutamine}

\subsection{Tallinna kaart}

Alustuseks: Kausi tegelased avastavad ja kaardistavad kangekaelselt linna, kannavad valgele alale aina tänavanimesid. Linn tekib, nagu öeldud, kõndides või sõites ,jalutamise retoorika" kaudu - jalakäijad kirjutavad linnateksti, on Kaus nõustunud Michel de Certeauga (vt Kaus 2005). Kaart näibki olevat üks oluline mõiste, ja seda mitte pelgalt nimetamise vahendina. Kartograaf loob maailma, püüab maastiku kaardile; tema valib ja otsustab, mida ja miks ta nähtust ja erinevail viisil vastu võetust kaardile kannab. Seesama toimub Kausi raamatutes, olgu kartograafiks siin tegelane või jutustaja, ja isegi kui kirjeldatud Tallinn püüab kohati olla kõikehõlmav, on mõned kohad kahtlemata läbivalt olulisemad kui teised. Osa kaardirännakuid oleksid justkui kantud otse topograafilisest orienteerumisvajadusest, korraliku kaardi olemasolu igatsusest. Näiteks antikvaar Andres Susmar romaanis „Koju”, olles osalt orienteerumisvõimetu, sest lapsepõlves läbi elatud ehmatus on võtnud temalt võime linna ruumiliselt tunnetada, kogub vanu Tallinna kaarte (Kaus 2012: 12). Võimalik muidugi, et Tallinn ongi vaatamata oma suurlinna mastaabi puudumisele raskesti haaratav, nagu Aare Pilv kirjutab „Ramadaanis”: „ta pole ei haaratav ega ka suurlinn” ning tundub „üle oma mõõtmete kasvanud väikelinnana" (Pilv 2010: 282).

Kaardiga aga piirduda ei saa: lugedes tekkiv linnakujutlus kaldub sealsamas enam kompleksse maastiku kui väljajoonistatud tänavakaardi poole, kirjeldus haarab rohkeid tasandeid. Kausi tegelaste linn on järsku nagu ruumilisest lasteraamatust pärit. Esiti luuakse tänavate kaart (Vanaturu kael - Raekoja plats - Voorimehe tänav - Pikk tänav jne, Kaus 2012: 127). Siis moodustavad ühe liigutusega vertikaalse ruumi mingid olulised hooned ja tänaval liikuvad objektid, „[p]isarateni vihased autobussid talvisel Hendriksoni küürul undamas" (Kaus 2012: 132) - ent need on üsna ebatavalised, pigem olevuslikud. Seejärel tekib viimaks teistmoodi aistitav ümbrus: on suvi, kastanilehed on linnaõhust tumenenud (Kaus 2012: 147); niisugune keskkond hakkab omakorda lehkama ja häälitsema, eritama „aguli tüsedat lõhna”, sõidukite heitgaasipilvi, higi ja grill-liha hõngu, noorte kehade erutust (Kaus 2009: 154). Kogu kaardile püütud ruum on justkui kehaliselt läbi tunnetatud - ikkagi läbi kõnnitud - ja tuuleiilist tolmu ning helini mingi leppemärgiga kaardile kantud, maastikku kinnistatud. 


\subsection{Tallinna linnamaastik}

Üks võimalus on tõlgendada Kausi Tallinna-kirjutust, ühe linna kujutamist ilukirjanduse vahenditega kui ühe linna mälumaastiku võimalikult ammendavat loomist, kui p a ig a tõepoolest ruumilist kujutamist. See on visand, kus linnamaastik koosneb sellel asuvatest objektidest, aga sõlmub samas neist tõukuvate tunnete, mälestuste ja unistuste, linlase argipäeva ja mõtteilma iseäralikuks konglomeraadiks - umbes nii, nagu maastiku mõistet seletab kultuurigeograafia (nt Cosgrove 2008). Selline linnamaastik on ilmselgelt kollektiivne loome. Isegi juhul, kui see on peamiselt just „autori enda mälestuste linn" (Helme 2013: 734), jääb ühise tõlgenduse võimalus seetõttu peale, et Kausi teostes on enamasti mitu vaatenurka: paralleelselt vaatavad linna vähemalt kaks tegelast, näiteks Eda ja Joosep romaanis „Hetk”. Kolme mehe Tallinna-nägemust kujutavas romaanis „Koju” on nähtud korraga linnaruumi ja linnamälu kirjeldamist, koha panoraamportreed (Vaher 2013: 109).

Kausi Tallinna maastikul leidub kõigepealt väga palju iseloomulikku, mida korduvalt kirjeldatakse. Näiteks on Tallinn kirikutornide ja tehaste linn, tornidest näib domineerivat Niguliste, siin asuvad ka teletorn ja peegelhotellid. Samas pole see kokkuvõttes „ei liha ega kala, ei Lääs ega Ida, ei küla ega linn”, vaid „väikese ilusa südamikuga, kivilahmakatest, pudedast puust ja asfaldist korrapäratu, lagunev keha, kus ükski kehaosa ei sobi veatult teisega kokku" (Kaus 2009: 154). Siitki lähtub asjaolu, et linn on igasuguste erinevate aistingutega seotud, ehtne meeltemaastik (vt Bunkše 2012: 60), näiteks huvitavatest välimistest teguritest tingitud lõhnamaastik, mille loomulik osa on isepäraste aroomidega seotud tänavad. Eriti „Tallinna kaardis” lisanduvad mitmed huvitavad linnalõhnad, olgu nende allikateks siis kohv ja friikartulid, kastanid, pärnad ning närtsinud lilled. See on ka valguse ja soojuse hilissuvemaastik (Kaus 2014b: 14), sealsamas inimesest endast alguse saav üksilduse maastik (nagu tundub olevat näitleja Asko Oksa Tallinn romaanis „Koju”). Oma roll sellise linna äratamises on kindlasti just peentel paiga- ja tüübikirjeldustel (Tammik 2014), nende valulisel täpsusel (Liivamets 2009). Mõnedki hõllandused on pigem kirjutatud linna õhku kui maastikule endale. Näiteks on „Tallinna kaardis” kirjeldatud ühtainust sumedat suve saabumise õhtut Tallinna, hetke, mil valgus peegeldub akendel, härrasmehed laenavad pintsakud daamide õlgadele alles kesköö paiku, õied lõhnavad nagu „naised, kes on esimese kallistuse ootuses heitnud jalast sukad" (Kaus 2014b: 26). Sellisesse suvisesse Tallinna kuuluvad pärnaalleede säbruline katus, Nõmme mändide kuldne valgus, mis avardub linna kohale, aga ka hüpoteetiline sekvoiapark, justkui igavese suve pelguses tekkiv kujund (Kaus 2014b: 12, 14, 16).

Kausi linnakirjutuses tekitatud linnamaastik on nagu prantsuse geograafi ja filosoofi Augustin Berque’i miljöö või médiance, ruumiline ja dünaamiline protsess, mis kätkeb sel maastikul toimuvat pidevat loomist, mõistmist, tundmist, lugemist ja väljendamist (vt Kasemets 2014: 460-461). Või atmosfäär saksa filosoofi Hermann Schmitzi mõistes, mis loob silla sisemise ja välimise maastikukogemuse vahel, olles aga subjektiivsem ja tundelisem, seotud inimese kiindumusastmega sellesse kohta: kui miljöö visualiseerib maastikku teadlikult, siis atmosfäär on seotud seletamatute, nihkes kogemustega (Kasemets 2014: 461). 


\subsection{Läbikirjutatud Tallinn}

Võiks nentida, et Kaus kirjutab huvitavalt uuesti läbi ka varasemas ilukirjanduses kujutatud linnamaastiku. Mõned asjad justkui ei muutugi kunagi. Linn on ikka veel niisama vertikaalne nagu Eduard Vilde ajal, tegelased tulevad linna väikestest puust agulimajadest, agul on ikka veel hierarhiline ja linnaruumis perifeerne. Aguliaias kasvavad sirelid nagu Marie Underi luules või väikese Illimari esimese linnaskäigu mälestustes Tartu jõeäärsest tänavast. Agul haiseb - võrreldes A. H. Tammsaare või taas Vildega on hõng lihtsalt osalt teistmoodi kui varem: nüüd annavad sellele „mündi” tähtaja ületanud toidukaubad, viledad dressipüksid, määrdunud kahekümneviielised, liisunud õlu (Kaus 2009: 154). Teisalt on midagi täpselt nii nagu kunagi enne: pööningul kuivava pesu, puitbriketi, korstnate suitsu, hallitanud ja seenetanud puidu hõng (Kaus 2009: 154, 157). Maie Kalda on maininud eesti kirjandusliku aguli lõhnu kui seda kanti juba psühholoogilisel tasandil iseloomustavaid (Kalda 2001: 1718). ${ }^{2}$

Kausi Lasnamäe on töölisbarakk, hiidmagala (Kaus 2009: 82) nagu Vilde Liivapealne, Sibulaküla või Joaoru. Tallinn on ka siin kunagi elanute, nüüd aga surnute linn (Kaus 2009: 70) nagu baltisakslase Werner Bergengrueni pajatuste moodi novellides kogumikus „Surm Tallinnas” (1939, e.k 1966). Vanalinnasüda on niisama võoras kui Karl Ristikivi romaanis „Õige mehe koda”, kus sellele vastanduv uus linnaosa, Lambapea tänav, kerkib heinamaadele: „Tallinna kaardi” peatükis „Sügise tänav” mõtleb ta, et Toompea ei ole kuidagi Tallinna keskpunkt (Kaus 2014b: 49). „Hetkes” on jäädvustatud paneellinn: „Vaid mõne lausega on heidetud üldistav vaade Lasnamäele, ja see ei jää kujutuslikult alla visuaalsele panoraamile filmis „Sügisball” (Liivamets 2009). Aga sealsamas on olemas ka Mati Undi romaani linnaosa ekvivalent, ehtne „Sügisball 2” aastakümneid hiljem: „Nende all elas oma elu Mustamäe, tuul tembutas peente liivajoontega asfaldil, prügikastidel istus kajakaid ja kasse, mõnikord ukerdas lagunevate telliskivimüüride, tuhkhalliks moondunud liivaga mänguplatside ja roostes, kuid ikka veel vaibakloppimiseks sobivate metalltorude vahel määrdunud inimesi, kes avasid prügikastide suid ja otsisid sealt õllepurke. Lapsed mängisid suitsukonide ja muu väiksema prahiga sõbralikult segunenud liivas, pooleldi purukspekstud liumägede vahel” (Kaus 2009: 115). Uudsuse võlu on sellelt küll igaveseks riisutud.

Kausi loodud linnas armastatakse ka distantsilt, läbi klaasi, mida on samuti varasemas ilukirjanduses kujutatud, ehkki erinevalt Arvo Valtoni novellist „Mustamäe armastus” ei krooni akna kaudu tuntud kiindumust lapse sündAsko Oksa ja Kristi salapärane suhe romaanis „Koju” jääb igas mõttes viljatuks ja on sedavõrd südantmurdvam. Linnast võib ära minna elekter: meenub jälle Mati Unt, „Öös on asju”. Ning Kausi linnas kohatud tantsija - näiteks „Hetke” Joosep - ronib kõrgele linna katuste kohale nagu Balthasar Russowi kroonikas kirjeldatud köielkõndija ning Jaan Krossi romaanis „Kolme katku vahel" noore Russowina sedasama imeturnijat piiluv poisike Pall-Balthasar.

\footnotetext{
${ }^{2}$ Lõhn võib olla terve omaette linnateema, kui meelde tuletada XVII sajandi Tartut Meelis Friedenthali romaanis „Mesilased” (2012).
} 


\section{Antitees: unenäoline, pooleldi seletamatu „miski” ehk linlase linn}

Kas tulemuseks on armastust, kiindumust, aga ka hirmu ja ängi objektidesse siduv Tallinna maastik, neid tundeid üha uuesti mõtestama ajendav miljöö? Või on see salapärane atmosfäär, inimese tundeilm, mis projitseerub hoopis linnale ja pakub sellest uue, avarama, üldistavama, mitte enam ühte linna klammerduva pildi?

Antikvaar Andres Susmar teab pisiasju „kusagilt Toompea pööningult leitud hallitanud kiikhobusest" (Kaus 2012: 13). Tema teadmised võiksid ju olla kuidagi iseloomulikud ka Kausi romaanide linnamaastikule - ühtpidi saab kiikhobusest teada valmimise aastat, värvi, materjali, isegi väikese omaniku nime ning lelu omandamise või kaotamise asjaolusid.

Jääb aga terve hulk asju - ka fakte, kindlasti aga tundevirvendusi, kiindumusastmeid -, mida teab ainult suksu kunagine omanik. Need on talle edasises kiikhobusest väljakasvamise elus millegi suurema alguseks, nende põhjal hakkab ta kogema maailma.

\subsection{Tallinna avardumine}

Kausi kirjanduslike linlaste poolt tajutav ja edasi antav Tallinna-miljöö on muutlik ja ajendab uusi tõlgendusi, ent ikka ja jälle otsitakse linnas/elus just oma kohta ja sellele kohale seletust - mitte ainult ühes kirjeldatud kohas, vaid maailmas üldse. Umbes nagu Unt kirjutab „Sügisballis” mitte ainult Mustamäest, vaid „lausa aistitavat teksti, detailselt fikseeritud seisundeid, peeneid meeltemuljeid, mis näitavad lugejale maailma nagu esmakordselt. Tähtis on tunne, hetk, pilt, mitte story" (Hennoste 1993: 61).

Nii võibki küsida, seda eriti Kausi viimase Tallinna-raamatu, „Tallinna kaardi" kohta: kas Kaus enam kirjeldabki põhieesmärgina Tallinna kaarte või maastikke? Tegelikult on ta juba 2002. aastal pakkunud välja oma linnaruumi mõtestamise viisi - kui olukorra, kus linn ei määra inimest, vaid „inimene paneb linna lõpmatu rahutusega vibreerima" (Kaus 2002). Maire Liivamets on märkinud, et Kaus „tajub linna kui tervikut, kuid inimesi märkab indiviidide ning üksiklastena selles väiksemõõdulises, kuid kaootilises kohas" (Liivamets 2009) - see on iseendast oluline väide. Kausi romaanide linnaruumi on peetud ängistavaks ja painajalikuks, mille põhjusi on erinevalt tõlgendatud - näiteks igavese provintsilinna täitumatu suurlinlikkuse ihalusena (Tammik 2014). Iseäralikku painajalikkust tekitavad ka needsamad eespool mainitud tegelaste lõputud, aga samas kuidagi rutiinsed jalutuskäigud, mis allutavad kõndija „keha... linna käsikirjalise „teksti” jämedatele ja peentele joontele; nemad [jalakäijad] kirjutavadki linnateksti, ehkki ei suuda seda ise lugeda" (Certeau 2005: 152). Kausi tegelased ei suudagi kaua linna/maailma „lugeda”, ehkki püüdlevad nii väga selle poole; nad ei vabane enne linna/elu ängist, kui omandavad selle võime. Nad on tõepoolest väiksemõõdulised ja üksildased, neist lähtubki justkui ruumilist ebakindlust, suutmatust oma elupaigas end kindlalt tunda: ehkki Tallinn on kalju peale rajatud, on ta Juri Lotmanist lähtudes siiski ekstsentriline, ebakindlalt mere kaldal asuv linn (Lotman 1999: 328). Selliste tegelaste omamoodi koondkuju on „Tallinna kaardis” kohatud preili Laboratooriumi tänaval, „kes tuli rõdule unistama ja paemüüri vahtima, ühel päeval paisutas rinda rõõm, järgmisel tundis ta, kuidas see kitsas tänav ja kitsas rõdu teda lämmatasid" (Kaus 2014b: 44). 


\subsection{Maailmaäng}

Romaani „Koju” üht peategelast, filmikriitik Rasmus Susmarit kummitab unenäomäng, mis toimub inimtühjas Tallinnas: ta peidab end vaenlaste eest, kes teda jahivad ning lõpuks tabavad - see on isegi omamoodi kergendus. Päris inimesteta linnadest saavad üldiselt kummituslikud paigad, khmeeride Angkor: liaanid põimuvad liivakivist templitesse, seos inimelanikega hajub iga aastaringiga üha enam.

Mõni selline linnaruumiga seotud hirmuunenäo põhjus peitub muidugi otseselt ikkagi linnaruumis, kus maastik omab/peegeldab/võimendab oma ajalugu. Näiteks läbivad Tallinna mälestuslikku linnaruumi mingid täna peaaegu nähtamatud, ent ajalukku kinnistunud võtmesündmused, mis ilukirjanduses vastu kajavad - vanasti 1905. aasta revolutsioon (Tammsaare, Ristikivi, Aadu Hint), nüüd näiteks 2007. aasta pronksiöö. Mingisugune katastroof, olgu kujutluslik või kunagi toimunud - 1944. aasta märtsipommitamine, kogu linna haarav elektrikatkestus, juba mainitud pronksiöö, Rasmus Susmari unenäomäng tühjas linnas -, on Kausil ühe tegelasi painava mõtte (taas)-tekitajana teksti sisse kirjutatud. Romaanis „Koju” lahvatab elektrikatkestuse kaudu ühe tegelase silmanägemise kaotanud vanaisa pimedus üle kogu linna (Vaher 2013: 109), see on Teise maailmasõja mälujälg. ${ }^{3}$

Ent ajaloost võnke ja võimenduse saavate sündmustega samavõrd kaalukad on tegelaste „lihtsad” juhtumused nende enda elust, mis aga võinuks juhtuda ka ühes täiesti nimetus (kirjanduslikus) linnas. Fotograaf on romaanis „Hetk” jäädvustanud armastajad Eda ja Joosepi suvisel Toompuiesteel, temale tähendas paar vaid kompositsiooni osa, „vajalikku elusat laiku tänavajoonte vahel" (Kaus 2009: 10). Eda ja Joosep meenutavad seda hiljem kui hetke enne millegi purunemist, ometi on see mälestus, mida nad mõlemad vajavad, millest saab alguse omamoodi ärkamine ja uus elu. Joosep näeb fotot alles aastate pärast ja tema silmis koondub mustvalgesse momenti lootus ja rõõm, noore naise hele ilu ja õnn, kui „päevavalgus justkui silitas armunult ta nahka” (Kaus 2009: 167). Kastanilehed pärgavad armastajaid ja tänavat, mis lihtsalt peab olema niisama hele, suvine, helge. Romaani lõpp veenab, et Joosep oskab teisel korral elus ära tunda selle, millest tuleb kinni hoida. Ta ei pea selleks tagasi Toompuiesteele minema.

\subsection{Linlase hingekaart}

„Tallinna kaart” toob juba ridamisi sisse selliseid atmosfäärivõnkumisi, mis seovad tegelase ühtpidi lõdvemalt linnaga, teisalt aga annavad võrratult edasi just inimese hingekaarti, kui selline asi olemas on. Imeline miniatuur „Tallinna kaardis” on näiteks „Endla tänav” (Kaus 2014b: 48). Kui Tallinna tunda, olla seisnud kuskil sealsamas Kassisaba-Tõnismäe nurgal, siis on see tekst kahtlemata sõlmitud ka sellesse ruumi: Tõnismäelt langevasse kivisesse Endla tänavasse. Ent ühtlasi on see rännak ühe mureliku noore naise hinge, tunnetesse ja hirmudesse, mis on ehedamad kui tema sammude all varjudeta valguses tänav - viimane võimendab neid, annab neile ruumilise võrdpildi. Tema/lugeja on prii tänavarägastikust, mis veel romaanis „Koju” segadusse

${ }^{3}$ Sellest, kuidas ühes linnaruumis esialgu mitte haakuvad sündmused üheks tekstiks põimitakse, on suurepäraseks näiteks ansambli Velikije Luki muusikavideo „Tallinn põleb” (https://www.youtube.com/watch?v=gzHYPNJ7vP4). 
ajas (Riismaa 2012). Ning ehkki seesama miniatuur kirjeldab rasket hingelist olukorda, on siin lootust: terve „Tallinna kaart” on helgem võib-olla just seeläbi, et ei olda oma ruumi vangis, vaid tuntakse end selles kodus.

Varem olen seda olekut „Tallinna kaardi” puhul kirjeldanud tundekaardina (Talivee 2014), nõnda lõpetab miniatuuridekogumiku ju Kaus: „Mul poleks selle vastu midagi, kui mu aknale oleks kleebitud mu tunnete kaart" (Kaus 2014b: 51). Kaarti on talletatud emotsioonid, muljed, ärkamised ja tõlgendused, mis võivad - aga tingimata ei pruugi - äratada lugeja oma (Tal)linna. Ta asemele astub ma. Eriti hinnatav on seejuures Kausi $m a$-vormi mitmehäälsus, kord ühest, kord teisest soost, võib-olla isegi igas loos erinev.

„Tallinna kaardis” võimendub linn kui inimeste lugu, kui paljude inimeste lood ühes rahutus tänapäevases kohas, kui see ka ei ole suurlinn. Iga sellise inimese lugu avaneb kiikhobusega sarnaselt vaid osaliselt lihtsalt; ülejäänu jätab võimaluse sellekssamaks „miskiks”, mida ei pea suutma alati lahti seletada. Kummituseks, unenäoks. Selleks, mis ilukirjanduses vastu heliseb, aga mida ei tohigi minu arvates saada lõplikult seletada, muidu kaotaks ta oma võlujõu.

\section{Kokkuvõtteks}

Kas peaks siinkohal sünteesina saama kokku võtta arusaama, et linn on inimesed, mitte artefakt? Peeter Helme on kirjutanud: Tallinn on ise tugevaim tegelane, näiteks romaani „Koju” „kõige elusam karakter”, mis annab oma elanikele koha ja õigustuse (Helme 2013). Kas on? Jah, sel juhul, kui see on linn, mis ikkagi tekib inimestest, nende elukaartidest. Kaus ei jutustagi niivõrd ühe linna lugu: ta kujutab linnainimese lugu Tallinnas; tema teed (siin) linnas: minu meelest on see oluline. Geoff Nicholsoni parafraseerides: linnakaart ei ole enam vajalik, kui on rajatud uus linn, mitte see, mis on tehtud kivist ja tellistest, betoonist ja bituumenist, vaid selline, mis on loodud mälust, kujutlusvõimest ja kinganahast. ${ }^{4}$ Vahe on siin õhkõrn, kohati tõesti tunnetuse küsimus.

\section{Kirjandus}

B u n k š e, Edmunds Valdemārs 2012. Geograafia ja elamise kunst. Tallinn: Varrak.

C e rte a u, Michel de 2005. Igapäevased praktikad I. Tegemiskunstid. Tartu: Tartu Ülikooli Kirjastus.

C o s g r o ve, Denis 2008. Geograafia on igal pool. Kultuur ja sümbolism inimese maastikes. - Vikerkaar, nr 7-8, lk 70-97.

H e $1 \mathrm{~m}$ e, Peeter 2013. Jah, vigadega - aga suurepärane. - Looming, nr 5, lk 734-735.

Hennoste, Tiit 1993. Mati Unt. Mälestused ja lootused. - Vikerkaar, nr 12, lk 60-63.

K a l d a, Maie 2001. Eesti kirjanduslik agul. - Looming, nr 11, lk 1715-1726.

$\mathrm{K}$ a s e m e ts, Kadri 2014. Visual meaning-making in an underprivileged neighbourhood landscape: milieus and atmospheres. - Visual Communication, kd 13, $\mathrm{nr} 4, \mathrm{lk} 459-470$.

K a u s, Jan 2002. Jalutades Vana-Kalamaja tänaval. - Sirp 8. II.

${ }^{4}$ „They're no longer necessary since I have created a new London, not one made out of stone and brick, tarmac and concrete, but a London created out of memory, imagination and shoe leather”. Tsitaat Geoff Nicholsoni romaanist „Bleeding London”, 1997 (vt Schechner 2007). 
K a u s, Jan 2004. Tallinn: ühe linna lugemise ühest võimalusest. - Vikerkaar, nr 4-5, lk 64-73.

Ka u s, Jan 2005. Rohtunud rajad linna nähtamatul kaardil. - Ehituskunst, nr 43-44. Arhitektuur ja meedia. Tallinn: Eesti Arhitektide Liit, lk 46-50. http://ehituskunst.ee/jan-kaus-rohtunud-rajad-linna-nahtamatul-kaardil (7. V 2015).

K a u s, Jan 2009. Hetk. Tallinn: Tuum.

K a u s, Jan 2012. Koju. Tallinn: Tuum.

$\mathrm{K}$ a u s, Jan 2014a. Ma olen elus. Tallinn: Tuum.

K a u s, Jan 2014b. Tallinna kaart. Miniatuurid. - Loomingu Raamatukogu, nr 20. Tallinn: SA Kultuurileht.

K a u s, Jan 2015. E-kiri E.-M. Taliveele 7. IV.

Li iv a m ets, Maire 2009. Jan Kaus. Hetk. - Kirjanduse ja keele ajaveeb. Rahvusraamatukogu kirjanduse ja keele asjatundjate arvamusi, 7. XII. http://kirjandusjakeel.blogspot.com/2009/12/jan-kaus-hetk.html (7. V 2015).

L o t m a n, Juri 1999. Semiosfäärist. Tallinn: Vagabund.

Pilv, Aare 2010. Ramadaan. Tallinn: Tuum.

R i i s m a a, Kaur 2012. Tallinlastest ja tallinlastele kirjutatud linnaromaan. Eesti Päevaleht 19. XI.

S c he ch ner, Brooke 2007. Thank you and goodnight... - Brooke's Blog, 19. XI. http://brookeslondongetaway.blogspot.com (7. V 2015).

S i b r i t s, Heili 2010. Jan Kausi lugu üksindusest ja lähedusest. - Postimees: AK 23. I.

T a li v e e, Elle-Mari 2014. Üks mitmekihiline tundekaart. - Sirp 10. IX.

T a m m i k, Toivo 2014. Jan Kaus. Koju. - Nihilist 22. X. http://nihilist.fm/kaus (7. V 2015).

V a he r, Berk 2013. Tallinn, Kausi-kujuline katkestusküla. - Vikerkaar, nr 3, lk 106-109.

\section{The personal city of Jan Kaus}

Keywords: Jan Kaus, cities in fiction, cultural geography, memoryscape and mindscape, city mapping, Michel de Certeau

Jan Kaus's approach to Tallinn in his prose is analysed. Using mapping, description, history, memory and memories of the place Kaus depicts the town through the views of different characters, while the motifs are often the same. The article examines whether the author prefers to describe the town or rather concentrates on the feelings and sense of identity of its inhabitants and on how it manifests in their interpretation of their town. As to the ways used to bring Tallinn home to the reader Kaus often chooses to convey a subtle cognitive milieu or atmosphere, connecting peoples' fates with the cityscape. Kaus's depiction of Tallinn often includes earlier texts on the town, while in his collection of literary miniatures Tallinna kaart („Map of Tallinn”, 2014) he captures the town as a state of mind, managing the soul map of a city person.

Elle-Mari Talivee (b. 1974), MA, Tallinn University, Estonian Institute of Humanities, doctoral student; Under and Tuglas Literature Centre, researcher, ellemari@utkk.ee 